\title{
Historical and pedagogical analysis of the process of global digitalization of education
}

\author{
Tatiana Rezer* $^{*}$ \\ Ural Federal University named the first President of Russia B. N. Yeltsin, 620002, Yekaterinburg, \\ Russia
}

\begin{abstract}
The purpose of the article is to conduct a historical and pedagogical analysis of the process of global digitalization of education, to determine the stages of this phenomenon, and to highlight the features of online learning. The objectives of the study are the analysis of sources on the digitalization of education, the definition of the "global digitalization of education" concept, the classification of the stages of this digitalization, and the definition of the main aspects of online learning. The methodology is the use of a comparative analysis of theoretical and practical sources of global digitalization of education. The lack of attention in modern research to the disclosure of the historical and pedagogical subject of this phenomenon was identified. The method of theoretical analysis was used to identify new realities in the educational process. The main aspects of the global digitalization of education were identified by applying the method of deduction and historical and pedagogical analysis. These aspects were classified to positive and negative lists by their impact on the participants of the educational process

The global digitalization of education is the technical and technological development of civilization, as a result of which there was a change in informational social development according to the scheme: informatizationdigitalization-artificial intelligence. It led to the new forms of thinking and socialization of the individual in the digital educational environment.

The phasing is from the $60 \mathrm{~s}$ of the last century and to the present, due to the rapid technological progress.
\end{abstract}

\section{Introduction}

The main challenge facing modern higher education is the educational process, its forms, methods, and technologies, as well as the quality of the final educational result. The key issue of the effectiveness of modern educational institutions of higher education is to increase the motivation of students and teachers in the global digital educational environment.

The COVID-19 pandemic has made significant changes in the organization of the higher education process. The abrupt transition from the traditional form of education to the online form and virtual educational environment has affected not only the quality of education but also the health of its participants. For a certain time, it seemed that learning in a virtual

\footnotetext{
*Corresponding author: t.m.rezer@urfu.ru
} 
educational environment is something far away and gradually penetrates educational relationships.

However, the COVID-19 pandemic was precisely the catalyst, the preventive measures and restrictions led to the urgent need to restructure the delivery of educational information exclusively through information technologies and digital educational resources.

Various areas of research are devoted to the development of the digitalization of education; the subjects of research in this area have a large multi-vector and interdisciplinary nature of research. It is necessary to agree with Starichenko's opinion that by analogy with the structure of the concept of "digital economy", the definition of "digital education" is also constructed as an educational activity in the form of online learning [1]. At the same time, the "digitalization of education" is interpreted as a transition from traditional education to digital education. Of course, there is a humanitarian resistance in society to the digitalization of education, which is proved by the study of the educational process in the context of the pandemic in 2020. According to the results of this study, the digitalization is perceived by society not so much as a technological modernization and the introduction of new media of educational information, but also as a process of dehumanization that threatens people and society. Murzina I. Y. notes that there is a loss of a meaningful component in a person's life in favor of accepted mechanical, artificial, and externally set algorithms and standards of action [2, p. 107].

According to Kondakov \& Kostyleva, a global educational experiment in the history of mankind is currently taking place. It has covered many countries of the world: $90 \%$ of kindergartens, schools, colleges and universities of the world, and the total enrollment of students has exceeded 1.75 billion people and more than 200 million teachers. These data convincingly prove the global nature of the digitalization of education [3]. Interesting studies are devoted to learning strategies in the context of digitalization of modern education and digital didactics $[4,5]$. In the modern world unlimited opportunities for self-development are provided to each person, which determines the deep transformation of human civilization. The digit is already considered as a didactic unit of educational information, and digitalization is also interpreted as the global problem in education that needs to be solved at the present stage of the development of our civilization [6,7]. Among the discussed problems, a special place is occupied by the analysis of distance and online learning in the digital educational environment, which is caused by the features of the virtual environment and new learning conditions $[8,9,10,11]$. Therefore, teachers are especially interested in the process of personal formation and the development of professionalism in a future specialist who has received an education in an unconventional form of education in a higher school.

The analysis of theoretical sources and other documents has shown that scientific works about the digitalization of education do not pay enough attention to the disclosure of the historical and pedagogical aspect, namely, the stages of the digitalization process and the pedagogical aspects of online learning in terms of their impact on educational activities and the participants of educational relations themselves.

The purpose of the study was to conduct a historical and pedagogical analysis of the process of global digitalization of education, that is, to determine the stages of this phenomenon and the features of digitalization of education in the form of online learning.

To achieve this goal, it was necessary to complete the following tasks:

- to analyze the sources devoted to the theoretical and practical aspects of the digitalization of education;

- to highlight the main stages of the process of digitalization of education;

- to propose a definition of the global digitalization of education;

- to formulate the positive and negative aspects of online learning.

The research hypothesis is: the process of global digitalization of education has several stages, which is caused by the technical and technological development of the information 
society, and online learning can have both positive and negative aspects, like any other form of education.

\section{Methodology of the research}

To complete the tasks several methods were used.

The comparative analysis of sources devoted to theoretical and practical aspects of the global digitalization of education was done.

The method of theoretical analysis was implemented to study the Russian and foreign experiences in the field of digitalization of education and new realities in the educational process.

The historical and pedagogical method was applied to analyze scientific sources and documents in the historical sequence of the development of the process of global digitalization of education and to distinguish three stages: the stage of education information; the stage of education digitalization, and the stage of education digitalization with the introduction of "artificial intelligence" in human life.

The method of deduction was used to identify the main aspects of the global digitalization of education and classify them into positive and negative aspects by their impact on the participants of the educational process.

\section{Results}

The growth of information as a special type of resource in society was outlined at the end of the 18th century, when the carriers of information were numerous sources in printed and other forms. However, the civilizational processes developed so rapidly and quickly that the time came when the processing of all new information became almost impossible for one person.

In the 20th century, this process was further spread and became the main characteristic of the digitalization of education. Many researchers point out that the socio-economic prerequisite for the "information explosion" was the technical development and scientific discoveries that led to an increase of information flows in human life and contribute to the development of the information society. New information technologies do not replace traditional ones: the amount of "paper" and "digital" information is not reduced. At present the information sources of various forms continue to grow, so there is a problem of preserving them for future generations, including in the education system as a social institution that transmits historical heritage and cultural values to future generations.

Informatization of society is the restructuring and enrichment of the information and communication basis for the functioning of society and its most important sub-systems of production, management, science, education, services, cash transactions, medicine, criminology, and environmental protection.

Along with the development of information structures, there has been a gradual "semiotization" of society, which is caused by the development of new knowledge systems that form a multi-component "information field". These include:

- short texts;

- graphic images of messages;

- audio and audio-visual messages.

Table 1 shows the selected stages of digitalization of education in the current conditions of globalization of education. 
Table 1. Classification of stages of digitalization of education

\begin{tabular}{|l|l|l|}
\hline Stage number & \multicolumn{1}{|c|}{ Stage name } & \multicolumn{1}{c|}{ Stage periods } \\
\hline First stage & Informatization of education & $\begin{array}{l}\text { in the } 60-90 \text { years of the } \\
\text { 20th century }\end{array}$ \\
\hline Second stage & $\begin{array}{l}\text { Informatization of education with the } \\
\text { transition to the digitalization of education }\end{array}$ & $\begin{array}{l}\text { from the } 90 \text { s of the 20th } \\
\text { century to 2016 }\end{array}$ \\
\hline Third stage & $\begin{array}{l}\text { Digitalization of education and was caused by } \\
\text { the introduction of artificial intelligence in the } \\
\text { life of a modern person }\end{array}$ & from 2016 to the present \\
\hline
\end{tabular}

As a result, the problem of communicative adaptation of a person in the information society has arisen, which is being solved by representatives of different sciences. The pedagogical community was the first to draw attention to this problem, and pedagogical practice encountered the phenomenon of "clip thinking" in high school students and schoolage children, which complicated the development of logical and critical thinking in students.

The first stage is the informatization of education in the 60-90 years of the 20th century. The theoretical basis for the informatization of society is computer science. The term "Informatics" has been introduced three times into Russian scientific usage. For example, in the 60 s of the last century it was used to name a scientific discipline about the organization of the search and accumulation of scientific and technical information. Its other meaning came from the French language (Informatique - information, automation) and it defined the science of automated processes of transmission, processing, and storage of information based on electronic computers.

Since the 80 s of the 20th century, there has been a qualitative change in the understanding of the term "computer science". This happened because of understanding of the concept of "informatization", which, according to Ershov, has become one of the active points of growth of philosophical science in recent decades. So in 1981, in Lausanne, A. P. Yershov made his famous report "Programming is the second literacy" at the III All-World Conference of the International Federation for Information Processing and UNESCO on the use of electronic computers in learning. The title of this report quickly became a slogan around the world and the impetus for future scientific discoveries in this field.

Among the specific socio-pedagogical characteristics of the informatization of education, the contradiction between the rate of increment of knowledge in society and the limited opportunities for their assimilation by the individual occupies a central place. Attempts to resolve this contradiction lead to the rejection of the absolute educational ideal - a fully developed personality, and would replace it with a socially determined educational ideal, that is, the development of human abilities for self-realization and digital self-identification.

And a person who does not possess information technologies loses one of the adaptive mechanisms in a dynamically developing society. Information tools and technology become a kind of information organs, "extensions" of a person. McLuhan's famous phrases "Medium is the message" and "Global village" ("global village" means the modern world) they have become established clichés [12].

At first, the term "informatization of education" in the mid-80s was used in the narrow sense of the word. In 1988 a group of scientists led by Academician A. P. Yershov developed the first Russian concept of informatization of education. It highlighted a number of directions:

- the formation of computer literacy as an element of general education training of a person;

- the development of content and methods of training based on information technologies;

- the use of electronic computers in the management of education [13]. 
The concept fixed the level of ideas about the process of informatization of education, computerization of training, and information-technical and organizational aspects of training in educational organizations of different types, and types that had developed by the end of the 80 s of the 20 th century. It was the first stage.

The second stage is the informatization of education with the transition to the digitalization of education from the 90s of the 20th century to 2016. In Russia, in the 90s of the 20th century, a new concept of informatization of education was created, in which the informatization of education was closely linked to the need to informatize the entire society. The new concept identified promising components for the purposes of education: computer laboratories, telecommunications (computer, audio-visual) and operational printing, interactive video systems, etc.

The third stage is the digitalization of education from 2016 to the present, and was caused by the introduction of artificial intelligence in the life of a modern person. Finally, in 2016, the federal project "Modern Digital Educational Environment in the Russian Federation" was launched; it was approved by the Government of the Russian Federation as part of the implementation of the state program "Development of Education" for 2013-2020. Within the framework of this project, the education system and vocational training were modernized, educational programs were brought into line with the needs of the digital economy, digital tools were introduced everywhere in educational activities, and the opportunity was provided for citizens to study according to an individual curriculum throughout their lives - at any time and in any place.

Digital transformation has now penetrated almost all areas of professional and scientific knowledge, as well as all spheres of human life. So in Russia, in February 2011, an initiative group of scientists created the public movement "Russia 2045". They are developing ambitious projects, for example, the "Avatar Technoproject", according to it in 2045 a body will be created - a hologram of a person controlled by a neuro-interface. The project provides for four stages of "human digitization": A, B, C, and D, during which the human mind will be gradually transferred to an artificial human. The given example clearly proves the reality of the introduction of artificial intelligence in the daily life of a person.

The historical and pedagogical analysis made it possible to classify the aspects of online learning in the context of the digitalization of education. The following circumstances relate to the positive aspects of pedagogical activity in online learning:

- this form of training contributes to the greater opportunities for the student to study additional materials and to obtain new sources of educational information, which is visualized using computer graphics;

- it opens up the possibility for students to be in virtual space and in time without restrictions in the process of mastering the educational material;

- it promotes continuous training of a specialist outside of his/her main professional and other activities;

- it opens new learning opportunities for people with disabilities;

- it promotes the formation of organization and discipline during the learning process, which is expressed in strengthening self-control over the results of educational activities;

- it reduces the student's time in public transport;

- it contributes to the creation of additional free time for studying other academic disciplines;

- it eliminates in some cases the psychological barrier in online communication situations;

- it increases the time spent with family and friends;

- it creates new digital competencies and provides online employment.

The negative aspects of online learning and digitalization of education are divided as follows: 
- computer illiteracy of some students and teachers makes it difficult to perceive the educational material and transmit it;

- there is a lack of information in the structure and content of the offered programs and courses on digital platforms;

- sometimes there may be technical problems and errors in the use of digital platforms;

- there is a lack of emotions in the interaction between the participants of educational relations;

- reduced motivation to learn comes from the lack of direct contact with the teacher;

- people may point out some tension and dry eyes, fatigue after prolonged work at the computer;

- sometimes there is a combination of household chores, communication with family and friends with the learning process, which interferes with the assimilation of information;

- there is a possibility of obtaining a biased assessment of knowledge both during the training process and during the session;

- there are cases when a student's personal workplace or a separate personal computer is not available;

- it opens the possibility of new forms of didactogeny.

\section{Discussion}

As a discussion, the following definition of the global digitalization of education is proposed: it should be understood as the technical and technological development of civilization, as a result of which there was a change in the stages of information social development according to the scheme: informatization - digitalization - artificial intelligence, which led to the emergence of new forms of thinking and forms of socialization of the individual in the digital educational environment.

As a result of the research, three stages of the process of global digitalization of education are proposed, starting from the 60s of the last century up to the present day - the era of artificial intelligence. As the basis of the proposed division into stages, the technical development of tools for informatization of educational activities, the use of digital platforms and digital resources in pedagogical practice were taken.

The theoretical analysis of the sources devoted to the global digitalization of education showed that different aspects of this multidimensional object of research were considered, starting with preschool education [14].

With the help of comparative analysis, the results of research on some aspects of the global digitalization of education were considered and it was found that the psychological aspects and personal characteristics of students during the transition to digitalization of education had been already studied $[15,16]$, the formation of students ' cognitive interest in the e-learning system and digital literacy had been also studied $[17,18,19]$, that gave an opportunity to characterize them as new realities in the virtual educational environment and formulate positive and negative aspects of online learning. The positive aspects of online learning are mainly mobility, employment, and visualization of learning. The negative aspects of the globalization of education are associated with the lack of a personal workplace of a student or a separate personal computer, the possibility of new forms of didactogeny because of the network nature of interaction in the construction of educational relations, which requires further study.

Currently, the term "digital education" is considered from different approaches. For example, the civilizational approach was applied and it showed that "digital education" as an element of the emerging new digital civilization, in which the digit is taken as an independent 
didactic unit, that is, a logically completed unit of the content of educational material that has its own goals and objectives of teaching.

From the point of view of the cultural approach, the ever-increasing digitalization of education should be considered as the other technological breakthrough in scientific development and as a dialectic of the new time - the third millennium. However, the question "What functions will be inherent in digital culture and what traditions will be the bearers of a person who has received training and education in a digital educational environment?" remains open. It is not clear how the business and personal qualities of a specialist who has been trained mainly in the distance form and mainly in the electronic format of obtaining educational information will change.

\section{Conclusion}

Digitalization of education and online learning are the reality of our lives, but the transition to online education does not mean a successful digitalization of education, despite its global nature and positive aspects for a certain category of people because their human mobility and health. The formation of new digital competencies and the provision of online employment is also a positive aspect of the digitalization of education. However, this component will require further research to determine the pedagogical conditions for their formation.

The tension and dryness in the eyes, fatigue after prolonged work at the computer due to severe inactivity - these are just the beginning of the list of the negative aspects of online learning related to human health, and this cannot but worry specialists in various scientific fields. The decrease in emotional health because of the decrease in the level of communicative activity of an individual in a virtual educational environment can also be pointed out.

The process of global digitalization of education is conditionally divided into three stages due to the technical and technological development of the information society. Online learning, like any other form of learning, has its positive and negative aspects, because of the pedagogical requirements for students' educational activities and digital media of educational information. Thus, there is a large scientific field for further research in the field of digitalization of education and online learning.

\section{References}

1. B.E. Starichenko, Pedagogical Education in Russia 3, 49-58 (2020) doi: 10.26170/po2003-05

2. I.Y. Murzina, The Education and Science Journal 22(10), 90-115 (2020) doi: 10.17853/1994-5639-2020-10-90-115

3. A.M. Kondakov, A.A. Kostyleva, RUDN Journal of Informatization in Education 16(4), 295-307 (2019)

4. A.S. Waskowska, T.A. Karpova, Science and Education: New Time 1(30), 738-746 (2019)

5. V.I. Blinov, S.N. Chistyakova, N.D. Podufalov, E.N. Gevorkyan, Modern problems of professional and higher education: State and assessment (Publishing House JekonInform, Moscow, 2019)

6. R.D. Sousa, B. Karimova, S. Gorlov, E3S Web of Conferences 159, 09014 (2020) doi.org/10.1051/e3sconf/202015909014, last accessed 2021/02/27

7. J. Devine, Personalized Learning Together. Open education 2030. Jrc-Ipts Call for Vision Papers (Part II: School Education, 2014). 
http://blogs.ec.europa.eu/openeducation2030/files/2013/05/Devine-OE-SE- 2030fin.pdf, last accessed 2021/02/27.

8. Z. Liu, N.V. Lomovtseva, E. Korobeynikova, Collaboration, International Journal of Emerging Technologies in Learning (iJET) 15(1)(3), 4-21 (2020)

9. D. Woldeab, R.M. Yawson, E.A. Osafo, E-Journal of Business Education \& Scholarship of Teaching 14(1), 1-24 (2020)

10. E.R. Vershitskaya, A.V. Mikhaylova, S.I. Gilmanshina, E.M. Dorozhkin, V.V. Epaneshnikov, Education and Information Technologies 25, 611-621 (2020)

11. M. Warschauer, Americas Quarterly 6(2), 131 (2012)

12. E. McLuhan, The Antigonish Review 5, 201-202 (1988)

13. A.P. Yershov, Introduction to theoretical programming. Conversations about the method (The Science, Moscow, 1977).

14. C.K. Blackwell, A.R. Lauricella, E.A. Wartella, Computers \& Education 77, 82-90 (2014)

15. B. Gurung, D. Rutledge, Computers Education 77, 91-100 (2014)

16. C. Freire, M. Ferradás, B. Regueiro, S. Rodríguez, A. Valle, \& J.C. Núñez, Front Psychol. 11(841), (2020) doi.org/10.3389/fpsyg.2020.00841, last accessed 2021/02/27.

17. C. Thomas, S. Zolkoski, Front. Educ 5(94), (2020). https://doi.org/10.3389/feduc.2020.00094, last accessed 2021/02/27.

18. A.A. Orlov, Pedagogics 10, 5-16 (2019)

19. I. Blau, T. Shamir-Inbal, O. Avdiel, The Internet and Higher Education 4, 100722 (2020) doi.org/10.1016/j.iheduc.2019.100722, last accessed 2021/02/27. 